\title{
Marcos legislativos, racionalidades político-económicas y ordenamiento territorial: La desarticulación sectorial y multinivel en México'
}

\section{Legislative frameworks, political-economic rationalities and territorial ordering: The sectoral and multilevel disarticulation in México}

\author{
Norma Rodríguez² (1)
}

\begin{abstract}
RESUMEN
El ordenamiento territorial es una propuesta que en México no ha logrado consolidarse en los diferentes niveles y escala geográficas debido a las tensiones que surgen entre las racionalidades político-económicas y el desarrollo territorial equilibrado, así como la desarticulación de los distintos sectores y la existencia de marcos legislativos y procesos de planeación del territorio deficientes. El objetivo de esta investigación es visibilizar los razonamientos de los legisladores, funcionarios y servidores públicos en la producción y aplicación de leyes, los intereses en conflicto, la sectorización normativa y la desarticulación multinivel que entorpece el curso de las iniciativas encaminadas a lograr una redistribución territorial equitativa. Se trata de un análisis desde la geografía crítica que a través del método dialéctico debate la propuesta de ordenamiento territorial en el marco de las tensiones que genera la estructuración integral y equilibrada del espacio, y resalta la importancia de adentrarse en las relaciones de poder e intereses ocultos que son determinantes en el éxito o fracaso de los procesos de ordenamiento territorial.
\end{abstract}

Palabras clave: Ordenamiento territorial, racionalidades político-económicas, marcos legislativos, desarticulación sectorial, conflicto de intereses

\begin{abstract}
Territorial planning is a proposal that in México has not managed to consolidate itself at different geographical levels and scales due to the tensions that arise between political-economic rationales and balanced territorial development, as well as the disarticulation of the different sectors and the existence deficient legislative frameworks and planning processes. The objective of this research is to make visible the reasoning of the legislators, officials and public servants in the production and application of laws, the conflicting interests, the normative sectorization and the multilevel disarticulation that hinders the course of the initiatives aimed at achieving a territorial redistribution equitable. It is an analysis from critical geography that through the dialectical method debates the proposal of territorial ordering within the framework of the tensions generated by the comprehennsive and balanced structuring of the space, and highlights the importance of delving into the power relations and hidden interests that are decisive in the success or failure of territorial planning processes.
\end{abstract}

Key words: Territorial planning, political-economic rationalities, legislative frameworks, sectoral disarticulation, conflict of interest. 
A lo largo de la historia han surgido distintas propuestas para resolver los problemas generados por el uso y apropiación del espacio, como el crecimiento caótico de las ciudades y la degradación de recursos naturales. Entre esas propuestas se encuentra el ordenamiento territorial que tiene su antecedente en el urbanismo europeo de finales del siglo XIX. Después de la segunda guerra mundial se convierte en la política idónea para la reconstrucción de las ciudades y regiones, mientras en Francia se conoce como aménagement du territoire, en Estados Unidos se conoce como land use planning. En América Latina los primeros intentos de ordenamiento territorial se dan en los años cuarenta con las políticas de desarrollo regional que buscan disminuir las disparidades derivadas de la concentración de población y actividades económicas, pero las primeras leyes y políticas públicas de ordenamiento territorial surgen hasta los años setenta.

En México, la política de ordenamiento territorial se ha caracterizado por la paulatina asimilación de políticas neoliberales con un fuerte componente ambiental. Las iniciativas no han logrado consolidarse en ninguno de los niveles y escala geográficas debido a las tensiones que surgen entre las racionalidades político-económicas y el desarrollo territorial equilibrado, así como la desarticulación de los distintos sectores, y la producción de marcos legislativos y procesos de planeación deficientes.

El ordenamiento territorial se ha conceptualizado desde distintos enfoques, las orientaciones generales ven en esta propuesta una técnica para ordenar el espacio (seres humanos, actividades, equipamientos y medios de comunicación) con una visión prospectiva, su finalidad es identificar, distribuir, organizar y regular las actividades humanas en el territorio (Valencia, 2009, Valenzuela, 2018). La Carta Europea de Ordenación del Territorio (1983), concibe el ordenamiento territorial como la expresión espacial de una política económica, social, cultural y ecológica, se entiende a la vez como una disciplina científica, un proceder administrativo, y una acción política que busca desde una práctica interdisciplinaria el desarrollo y orden regional equilibrado. Desde el enfoque administrativo se define como un proceso e instrumento de planificación con el que se pretende organizar el uso y apropiación del territorio tomando en cuenta sus potencialidades, limitaciones, los objetivos de desarrollo y las expectativas de la población, se trata de una política compleja que se apoya en instrumentos jurídicos, prácticas administrativas, información, conocimiento científico y participación, en busca de un tratamiento integrado en la planeación territorial (Massiris, 2006; Zoido, 1998).

La trama de relaciones de poder, los discursos y acciones de los distintos grupos de actores involucrados en el ordenamiento territorial y el alcance de las competencias entre distintos órdenes de gobierno, así como las prácticas de los gobernantes son temas que, desde una perspectiva crítica, ponen de manifiesto las tensiones, conflictos e intereses que permean la puesta en práctica de propuestas de ordenación territorial y contribuyen en el análisis conceptual, teórico y metodológico (Schmidt, 2014; Langbehn, 2013).

El ordenamiento territorial es un instrumento para construir un orden deseado, lo cual implica no sólo delimitar el pedazo de tierra, también implica ordenar el pensamiento, la divergencia de intereses para llegar a consensos, que generalmente no todos están dispuestos a construir, se enfrenta una serie de dificultades de orden técnico y político, de ahí que el orden deseado termine siendo el orden de unos pocos, generalmente expertos y políticos (Hernández, 2010). En el 
escenario de deslegitimación del Estado, las estructuras de orden económico y político se han desarrollado de manera autónoma apoyadas en la racionalidad instrumental (marcos legislativos, instituciones y normas territoriales) donde el dinero y el poder se vuelven los objetivos a alcanzar.

Los análisis críticos revelan la dificultad para construir verdaderos ejercicios de ordenamiento territorial por la existencia de conflictos e intereses ocultos que subyacen en los ejercicios planeación, estos estudios descubren las tensiones que genera el conflicto de intereses públicos y privados, las inversiones públicas que robustecen al sector económico, las políticas de vivienda y el auge del mercado inmobiliario como parte del proceso de reestructuración de las ciudades, entre otros (Santos, 2012; Valdebenito \& Álvarez, 2016; Neumann \& Hidalgo 2019).

En esta línea de análisis crítico se presenta esta investigación que muestra desde una perspectiva multiescalar el caso mexicano, haciendo énfasis en la construcción de marcos legislativos desarticulados y las racionalidades político-económicas que se imponen en la estructuración y gestión del territorio en todos los niveles administrativos y escalas geográficas. La información obtenida de los actores económicos y políticos revela las tensiones y conflictos de interés que impiden la emisión de leyes y programas de ordenamiento territorial adecuados para lograr un desarrollo socio-económico equilibrado.

El objetivo de este trabajo es visibilizar los razonamientos de los legisladores, funcionarios y servidores públicos en la producción y aplicación de leyes, los intereses en conflicto, la sectorización normativa y la desarticulación multinivel que entorpece el curso de las iniciativas de ordenamiento territorial. Las racionalidades político-económicas y los intereses ocultos constituyen un freno para la elaboración de instrumentos legales y normativos adecuados que contribuyan a evitar el recrudecimiento de los problemas territoriales. Desde este análisis dialéctico buscamos debatir la propuesta de ordenamiento territorial a la luz de las tensiones y conflictos por el uso y apropiación del espacio.

\section{Metodología}

La investigación se sustenta en los fundamentos del análisis social que plantean desentrañar los elementos que estructuran y organizan la capa visible de la realidad (que se presenta multifacética, caótica, dispersa y diversa), y la capa oculta, que permite ordenar la dispersión y cuestionar el orden aparente (Osorio, 2001). Se adopta la teoría crítica como paradigma que permite a través del método dialéctico vincular diversas ideas entre sí, y ajustarlas a la condición de una realidad que es relacional, dinámica, y a la vez estable y estructurada. (Carballido, 2015, Guba \& Lincoln, 2002).

Una de las técnicas metodológicas utilizada es el análisis de contenido, que permitió establecer las conexiones existentes entre diferentes elementos de textos recopilados y producidos, como leyes en materia rural, urbana y ambiental, planes y programas de desarrollo y plataformas políticas (Delgado \& Gutiérrez, 1999). Otra técnica que se implementó fue la aplicación de entrevistas semiestructuradas al sector gubernamental e inmobiliario en el estado de Michoacán y el municipio de Morelia. Entre 2017 y 2018 se realizaron ocho entrevistas a funcionarios y servidores 
públicos, en el nivel estatal y municipal, dos de ellas con legisladores, dos con regidores y cuatro con directores con competencias en las áreas de planeación y ordenamiento territorial, así mismo se realizaron dos entrevistas con agentes del sector inmobiliario. Las entrevistas tuvieron una duración aproximada de dos horas, algunos fragmentos son presentados de manera textual para dar sustento al argumento de este trabajo.

El territorio nacional en México se divide en 32 estados, los cuales a su vez están divididos principalmente por municipios. Desde la perspectiva del marco geoestadístico del Instituto Nacional de Estadística y Geografía (INEGI) los municipios están delimitados por AGEB, localidades (urbanas y rurales) y manzanas (ver figura 1). Según datos del del conteo del INEGI de 2015, en el país se registraron 119.938 .473 habitantes. A nivel estatal, en el caso de Michoacán se contabilizaron un total de 4.599 .104 personas. En la encuesta intercensal realizada en 2015 (INEGI), el municipio de Morelia registró una población de 784.776 habitantes, mientras la localidad de Morelia cuenta con una población de 597.511 habitantes.

Figura $\mathrm{N}^{\circ} 1$

Área de estudio

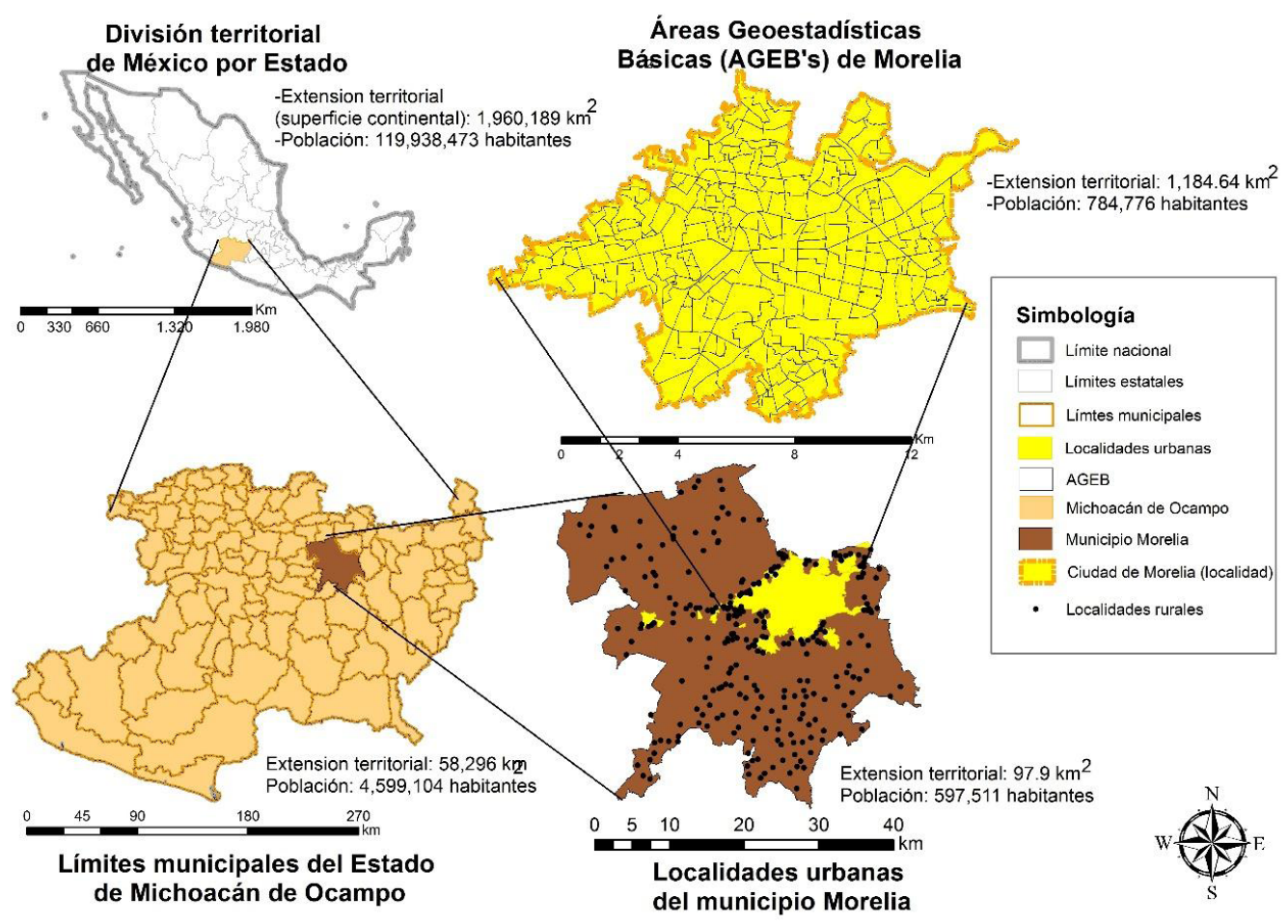

Fuente: Elaboración propia

En el tema de ordenamiento territorial Sánchez et al. (2013) identifica tres etapas, la primera va de 1940 a 1970 con el desarrollo de programas sectoriales y regionales, algunos con el objetivo de crear polos de desarrollo industrial y turístico. La segunda etapa es de 1970 a 1990, en la cual 
se emite la primera Ley General de Asentamientos Humanos en 1976 que establece el concepto de ordenamiento territorial de los asentamientos humanos y surgen los ecoplanes como primeros instrumentos de gestión ambiental. En esta etapa además, siguiendo las directrices marcadas en el informe Brundtland presentado en 1987 que intentaba terminar con la confrontación entre desarrollo y sostenibilidad, se emite la Ley General de Equilibrio Ecológico y Protección al Ambiente que incorpora el ordenamiento Ecológico como instrumento de política ambiental con impacto territorial, en consecuencia en 1996 se pública el manual de ordenamiento ecológico del territorio como primera metodología para realizar estudios territoriales en el país.

La tercera etapa se sitúa, de acuerdo con Sánchez et al., (2013), entre 1995 a 2012, en ella destaca la iniciativa de la Secretaría de Desarrollo Social de construir un grupo interinstitucional de ordenamiento territorial (GIOT), al que se integraría el Instituto Nacional de Ecología y el Instituto Nacional de Estadística, Geografía e Informática para impulsar los programas estatales y municipales de ordenamiento territorial con enfoque integral y de desarrollo sustentable. En este trabajo se discute la etapa más reciente que va de 2012 a 2018 donde se acentúan las tensiones y conflictos por el uso y gestión de territorio.

\section{La producción sectorial de marcos legales en distintos niveles y escalas}

Una dificultad a la que se enfrentan las iniciativas de ordenamiento territorial es el manejo de las escalas geográficas y niveles administrativos, así como los intereses que se superponen en cada nivel que, en muchos casos, reflejan orientaciones contradictorias (Hernández, 2010). Las políticas globales, inducidas por organismos supranacionales y por el mercado, tienden a configurar el marco jurídico-normativo de muchos países latinoamericanos, las firmas hegemónicas y los bancos toman el lugar de las instituciones gubernamentales y se insertan en los órganos de decisión para imponer reglas a todos los ciudadanos (Santos, 2014; Harvey, 2001). El Banco Mundial, por ejemplo, tuvo un papel protagónico en la formulación del Consenso de Washington, instrumento que refleja las relaciones de poder en medio de las cuales se desarrollan los procesos de restructuración económica y política que impactan de manera directa la planeación y ordenación del territorio (Gasca, 2013).

En el mismo sentido la Organización de Naciones Unidas, a través del programa ONU-Hábitat, establece una perspectiva planetaria para orientar la política de planeación y gestión del territorio, sus ideas trascienden al espacio local fomentando la modernización, innovación y competitividad territorial. Sin embargo, estas acciones no logran resolver de manera sustancial la sectorización y el conflicto de competencias en la producción de los marcos legislativos a los cuales debe ajustarse el ordenamiento territorial (Sauri, 1989). Además, la ingeniería jurídico-administrativa traslada a menudo formas implícitas o explícitas de modelos importados en búsqueda de la ley o el plan adecuados que no logra concretarse (Melé, 2016). Existe una parcelación en los temas rural urbano y ambiental, cada uno cuenta con su instrumental jurídico-normativo con competencias aisladas que limitan la interacción sustancial y la realización de acciones territoriales coordinadas (ver Figura ํ2). 
Figura $\mathrm{N}^{\circ} 2$.

Desarticulación sectorial y multinivel

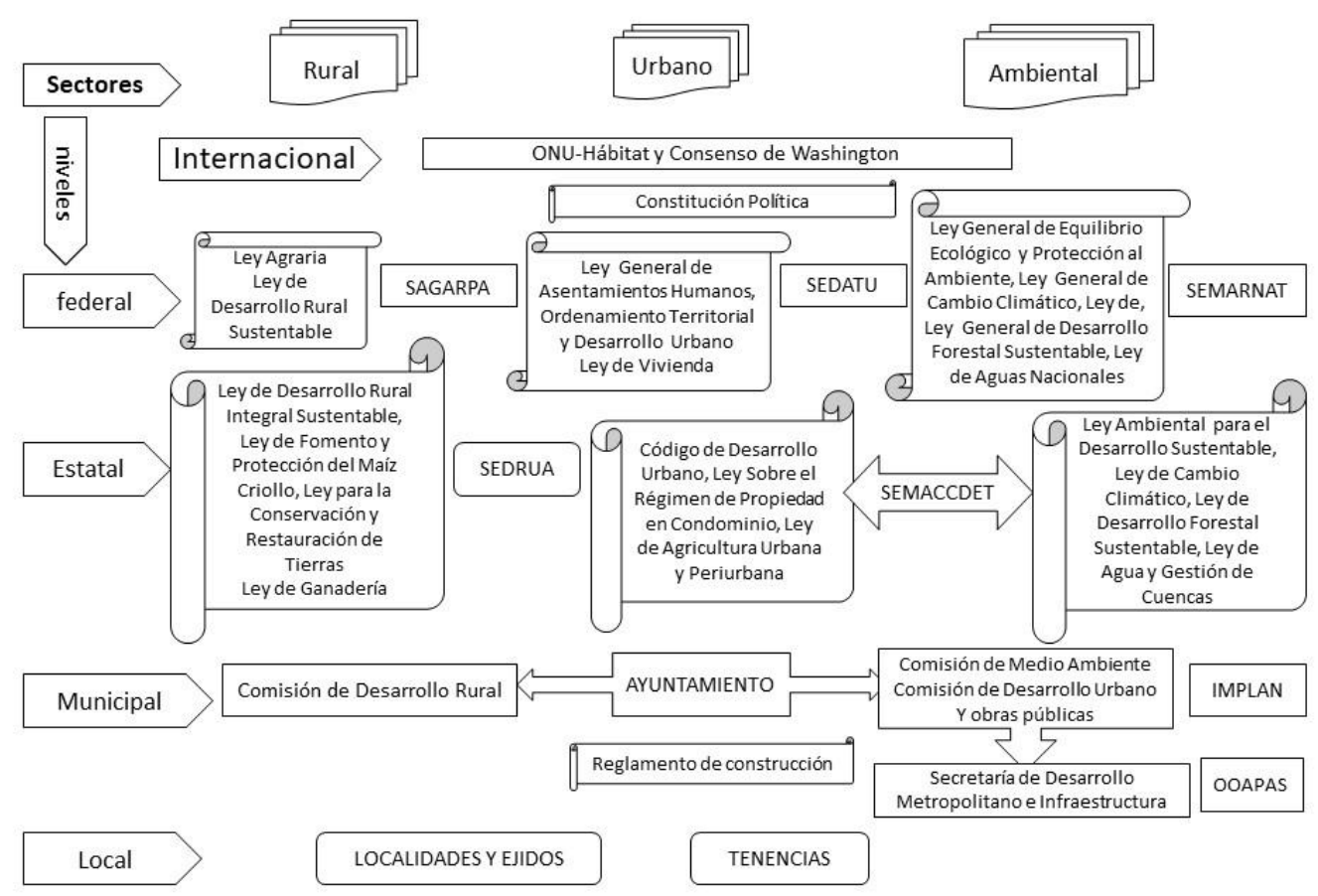

Fuente: Elaboración propia

Esa fragmentación y desarticulación de instituciones plantea la necesidad de una comprensión más amplia de los complejos patrones de asentamiento humano, uso y flujo de recursos naturales, capital, bienes y servicios para la elaboración de instrumentos que faciliten las iniciativas de ordenamiento territorial (Allen, 2003). Las clasificaciones jurídicas caracterizan y atribuyen funciones al territorio, las cuales pueden estar vinculadas con su apropiación, su protección o su destino. Como señala Melé (2016) es importante observar la representación que hacen del espacio y su capacidad de articulación o fragmentación:

Las clasificaciones jurídicas del espacio expresan ese carácter "performativo" atribuyendo una función social y una caracterización a un espacio: proclaman al mismo tiempo la apropiación jurídica y reglamentaria, la vigencia, la protección o el proyecto.... La naturaleza territorial de las clasificaciones jurídicas puede, por tanto, analizarse a partir de la capacidad que estas tienen de articular con base en los principios o restricciones que las mismas introducen, las representaciones del espacio, así como de ofrecer garantías sobre funciones, actividades, prácticas legitimas, y también sobre su futuro (Melé, 2016:48-49).

La segmentación legislativa, las constantes restructuraciones en los distintos niveles de la administración pública y la desarticulación de sectores impacta la organización y manejo del territorio. Los marcos legislativos distribuyen los derechos y deberes fundamentales (Rawls, 1997), 
en el nivel federal los temas rural, urbano y ambiental son regulados en la Constitución Política, la cual establece las bases generales para la atención de cada sector, con esas bases se emite un cúmulo de leyes y se crean instituciones sectorizadas. Sin embargo, la producción legislativa no ha logrado cubrir todos los temas y atender todos los conflictos territoriales, además las categorías legales y espaciales establecen clasificaciones, en ocasiones, arbitrarias (Blomley, 1992). En estos instrumentos se llega al absurdo de plantear como contradictorios la preservación y el desarrollo, con la construcción de leyes distintas que generan confusión, traslapes, esfuerzos innecesarios y multiplicación de costos (Eibenschutz, 2012).

Los cambios en el instrumental jurídico-normativo responden a las racionalidades político-económicas de los gobernantes en turno y los grupos de poder que inciden en la escena política. Los gobiernos federal y estatal establecen reglas generales y políticas estratégicas para la gestión territorial, mismas que marcan la pauta de la planeación y gestión de los gobiernos municipales. En esta lógica las distintas dependencias municipales operan políticas definidas en otros niveles, sin embargo, ejercen un poder importante en cuanto ejecutores directos de la política, apoyados por órganos desconcentrados de planeación municipal.

En este sentido, el flujo de racionalidades globales y nacionales de privatización, mercantilización y sustitución del conocimiento local por el uso de las técnicas (Santos, 2014), va en contra de una política de ordenamiento territorial sustentada en la equidad social a través la distribución equilibrada de equipamiento, infraestructura y servicios para superar fenómenos como la marginación de amplios sectores de la población, la degradación de recursos naturales, y la pérdida de la heterogeneidad cultural (Méndez, 2000).

\section{Racionalidades político-económicas en la ordenación del territorio mexicano}

En México las racionalidades político-económicas globales, federales, estatales y municipales están alineadas en temas específicos, eso permite a corporaciones mundiales y al gobierno alcanzar objetivos estratégicos que generalmente benefician a grupos reducidos de la población. Las realidades económicas, sociales y culturales de los territorios locales son invisibles en la planeación territorial, donde el espacio es simple contenedor de la acción política, objeto de extracción de recursos naturales que permiten capitalizar las inversiones de agentes privados (Castells, 1974; Lojkine, 1979).

La gobernanza neoliberal lleva implícita la aceptación de las normas del mercado por parte de los actores locales (Harvey 2001; Mattos, 2016), y promueve un sistema de competencias que separa las actividades legislativas de la planeación y ejecución, división que trasciende en los distintos niveles de gobierno y fragmenta las acciones territoriales, a ello se suman los cambios en las administraciones municipales cada tres o seis años y la falta de competencias en los operadores de la política:

El tema no es tanto quién opera, sino cómo se opera, cada administración aplica una política diferente. El municipio debe seguir asumiendo la rectoría en el tema urbano, pero en 
coordinación con el estado. El tema no solamente obedece a reglamentos estatales, también federales, y a veces la coordinación no se da, como debiera darse (Entrevista realizada el 13 de febrero de 2018).

La descentralización de funciones en el tema urbano ha sido polémica por el incremento de las problemáticas vinculadas a la gestión de las ciudades. La asignación de competencias, pérdida y recuperación de estas, así como la fusión o separación de sectores ha sido una constante que entorpece la consecución de planes territoriales. Los legisladores a nivel federal están inmersos en la incorporación de políticas globales al marco jurídico nacional, mientras las legislaturas de los estados se concentran en la homologación y reproducción de leyes federales, eso explica en parte los problemas de sobre regulación, la obsolescencia del marco jurídico, el diseño legislativo caótico y la complejidad y densidad de los instrumentos legales, así como los vacíos en la ley.

El administrador público es una especie de observador y verificador de normas que están desarticuladas entre sí, y que la propia iniciativa privada encuentra medios para articular, hay vacíos de poder, si ellos no coinciden y son armónicos, dejan un terreno para que quien tiene habilidades e interés en el tema logre hacerlo. Creo que hace falta articulación del sector público. No hay un solo programa que se lleve a cabo (Entrevista realizada el 13 de febrero, 2018).

La iniciativa privada aprovecha el caos que impera en la administración pública, derivado de la sectorización, desarticulación y los vacíos legales, para posicionar proyectos territoriales que generalmente tienen impactos negativos sobre el medio ambiente y fomentan la desigualdad social (Rodríguez et al., 2019). No obstante, desde la experiencia de los legisladores se considera que los conflictos territoriales están vinculados a la aplicación de las normas y no a la falta de regulación:

El problema está en quién ejecuta las leyes ies la autoridad desde mi punto de vista!, el código urbano es relativamente nuevo y se le han hecho parches, ahora requiere adecuarse a las reformas federales y el congreso está obligado a hacer estas homologaciones. El diseño legislativo depende de la Ley de Asentamientos Humanos federal y leyes en materia de medio ambiente, la comisión emitió reformas por los cambios en los nombres de las secretarías, y en materia de vivienda también se emitieron reformas enfocadas a la vivienda de interés social (Entrevista realizada el 13 de febrero de 2018).

La legislatura local está inmersa en la reproducción de leyes pensadas y diseñadas desde los escritorios de los congresistas federales, la actualización normativa derivada de las reestructuraciones administrativas es una constante. El derecho finalmente es un cuerpo de representaciones ideológicas del espacio, cuya función es mantener el orden social y gobernar de acuerdo con intereses económicos y políticos preponderantes (Lojkine, 1979; Harvey 2005; Castells 1974). La verticalidad del marco jurídico reduce la autonomía de los niveles inferiores de gobierno, las iniciativas que emergen para generar instrumentos intersectoriales fracasan ante los conflictos de interés que se generan entre los especialistas convocados.

Hicimos una revisión del código, artículo por artículo en 2012, se realizaron muchas reuniones con colegios de arquitectos, ingenieros, profesionistas, representación del congreso, el ejercicio se envió a todas las dependencias para que revisaran si había algo de su compe- 
tencia, pero creo que la integración de distintos sectores dificultó los acuerdos. (Entrevista realizada el 20 y 28 de septiembre de 2017).

En Michoacán, en la actualidad existen dos iniciativas de ley para tema urbano con intereses en conflicto, una de las iniciativas representa al sector empresarial y son muchos los recursos económicos que están en juego. El sector empresarial tiene otros mecanismos para hacer valer sus intereses, no necesita ir al congreso, el hoyo negro es el tema inmobiliario, cada gobierno estatal y municipal trae sus propios proyectos, unas administraciones frenan a ciertos desarrolladores de vivienda y dejan actuar a otros. Los empresarios inmobiliarios quieren seguir construyendo vivienda en la periferia por ello el tema de las densidades es el tema central en la ingeniería jurídica, ya que abre la posibilidad para capitalizar la renta del suelo:

El tema más delicado son las densidades, es un tema que ha salido a la mesa porque la iniciativa de ley plantea asentamientos humanos fuera del núcleo de población, hay una controversia en el tema de las densidades respecto a los documentos que se analizan, sobre todo de autorizarse ciertos asentamientos humanos, es uno de los asuntos muy delicados a revisar (Entrevista realizada el 13 de febrero de 2018).

El crecimiento disperso y segmentado de la mancha urbana es un fenómeno que se construye en los márgenes del Estado, pero no al margen de él, ya que tiene su origen en las definiciones cambiantes de lo legal y lo ilegal (Arzeno, 2019). Las ciudades dispersas y fragmentadas son resultado de presiones, mediaciones políticas e ilegalidades que se manifiestan por la falta de regulación en temas como el de densidades, que permite al sector inmobiliario avanzar en la consecución de objetivos de control y manejo territorial.

El control del desarrollo de la ciudad se lo dio hace varios años el estado a los desarrolladores inmobiliarios, ellos tienen el control y lo tienen a la medida. Que, si es bueno o es malo, es una discusión muy amplia, pero es un gran negocio para la autoridad también (Entrevista 08 de febrero de 2018).

Territorio, autoridad y derecho son instituciones complejas que se construyen a través de procesos específicos y surgen de luchas e intereses en conflicto (Sassen, 2006). Por ello la importancia de adentrarse en los conflictos, instituciones y relaciones de poder (fuerzas globales y locales) determinantes en la ordenación y gestión del territorio (Keivani \& Mattingly, 2007).

Los esfuerzos institucionales por vincular los sectores rural, urbano y ambiental, como la creación la Secretaría de Desarrollo Agrario y Territorial (SEDATU) en el ámbito federal, y la Secretaria de Medio Ambiente Cambio Climático y Desarrollo Territorial (SEMACCDTE) en el nivel estatal, son paliativos para posicionar discursos políticos, y resultan insuficientes porque no garantizan la coordinación de acciones. En Morelia el Instituto Municipal de Planeación (IMPLAN), es el responsable de generar instrumentos para el ordenamiento del territorio municipal, sin embargo, esta institución se ve rebasada por la dinámica de crecimiento de la mancha urbana, la intervención de diversos actores y los procesos de especulación del suelo:

Entendemos que la planeación es el eslabón de una cadena, otra es la administración, la ejecución, otra es la gestión, otra es la evaluación etc., y muchas veces nos encontramos 
con que no están claras esas interacciones y funciones de un sistema, y a veces se generan políticas aisladas y se duplican esfuerzos (Entrevista realizada el 05 de septiembre de 2017).

Los ajustes económico-estructurales y los procesos deficientes de planeación y gestión territorial son factores que contribuyen al recrudecimiento de los impactos críticos sobre el territorio donde aumenta la desigualdad y la destrucción de la biosfera (Mattos, 2019). La esencia del proceso de planeación está en la capacidad de lograr que la acción pública vaya delante de los hechos sociales, cuando el orden se invierte el proceso de planeación se desvirtúa y pierde sentido, la planeación sigue consumiendo recursos extraordinarios que no resuelven los problemas que competen al ordenamiento territorial (Eibenschutz, 2012).

Los consejos intersectoriales y de participación ciudadana generalmente se instalan para cumplir con la normativa en materia de planeación, en muchos casos sus integrantes defienden intereses individuales o de grupo, no existe una perspectiva ciudadana que persiga la producción de espacios sostenibles para todos (Sietchiping et al., 2014). Desde la perspectiva legal la participación ciudadana, además de controlar el poder político, busca incidir en las políticas, la administración, los proyectos económicos, sociales y culturales para alcanzar objetivos civiles y gremiales, la participación también esta segmentada en gremios y en algunos casos sirve para establecer las condiciones que permitan alcanzar los intereses de un sector. Además, los consejos consultivos o de participación ciudadana también están sujetos a los cambios normativos y de gobierno, así los esquemas de participación no se traducen en mecanismos efectivos para mejorar las condiciones sociales, económicas y ambientales en el territorio, no existe una conceptualización clara de la cual deriven las herramientas técnicas que permitan la apropiación por parte de los ciudadanos en todas las escalas espaciales.

Un tema controversial en el ámbito de la planeación es la generación de planes territoriales, estatales, municipales, estratégicos, locales, sectoriales (de desarrollo urbano, rural y ecológico), y parciales (Sili, 2019). Se emite una gran cantidad de instrumentos de planeación del territorio que se diferencian por la escala de actuación y el nivel de obligatoriedad, existen programas que son regulatorios y otros que son sólo inductivos, lo que determina la importancia de unos sobre otros.

Las escalas de los programas varían, pero los que se toman en cuenta son los regulatorios, que son del nivel municipal. Si no existen programas parciales, se aplica el del centro de población, si no existe se va al siguiente nivel, lo malo es que se va perdiendo el detalle. Ahora se intenta con los programas de ordenamiento territorial y gestión de riesgos a nivel municipal resolver problemas, pero se trata de un instrumento inductivo porque no está considerado en la ley, por tanto, no tiene sustento jurídico, lo que se hace es publicarlo como programa de desarrollo urbano para que tenga validez (Entrevista realizada el 20 y 28 de septiembre de 2017).

Desde esta perspectiva la legislación aplicable para ordenamiento territorial resulta insuficiente, con ello las iniciativas en el tema se debilitan. Además, el enfoque territorializado no se ha entendido como aquel capaz de identificar interacciones y conflictos entre agentes e instituciones, las disputas por las tierras y aguas, y el auge del mercado inmobiliario, entre otros (Ávila, 2016). No obstante, las deficiencias conceptuales y las condiciones de irregularidad jurídica en 
las que surgen los programas de ordenamiento territorial, las expectativas de las autoridades municipales son muy altas:

El programa de ordenamiento territorial nos dará los indicadores, derivado de eso buscaremos la actualización del programa de desarrollo urbano, necesitamos esas bases, el crecimiento debe darse según la existencia de recursos naturales, este programa nos dirá muchas cosas (Entrevista realizada el 14 de septiembre de 2017).

Cada nuevo programa de planeación que se emite se convierte en el instrumento que resolverá los problemas territoriales, se trata de intentos que depositan exageradas expectativas en las normas jurídicas para cambiar relación sociedad-naturaleza (Azuela, 2016). El programa de zona metropolitana ha generado controversia por los recursos que recibe del fondo metropolitano, la existencia de la zona metropolitana de Morelia ha sido un tema muy debatido con posturas que niegan su existencia dada la ausencia de interacción económica y social entre los territorios que la conforman.

Los recursos económicos para operar los programas son esenciales, sin embargo, en lo que se refiere a los programas de ordenamiento territorial difícilmente se decretan partidas específicas para su ejecución, así el resultado de los procesos de planeación son los propios planes, dada la desvinculación con la ejecución, implementación y evaluación, y los conflictos de interés que impiden su ejecución (Coulomb, 1989). Un ejemplo claro es el programa de ordenamiento territorial estatal, elaborado en 2015.

Por su parte el modelo planeación y distribución del ingreso encierra profundas desigualdades económicas, el gobierno federal se impone como recaudador y concentrador de facultades y recursos ejerciendo el $80 \%$ del presupuesto de manera directa, el $20 \%$ se transfiere a las 31 entidades del país, del monto que recibe Michoacán el 20\%, se destina a los 113 municipios, quienes reciben el $0.2 \%$ del presupuesto nacional, aproximadamente cada municipio recibe el $.002 \%$ (entrevista 20/09/20). El nivel municipal está desatendido por los niveles más altos de gobierno, de igual forma las estructuras que apoyan la labor del municipio, tenencias y encargaturas del orden, están desdibujadas en la proyección racional de los niveles superiores, incluso del mismo municipio.

Un instrumento de planeación que ha sido polémico es el plan de gran visión Morelia NExT elaborado por el Instituto Municipal de Planeación con apoyo de la consultoría Cities Lab de Fundación Metrópoli, en el trienio 2015-2018, este plan muestra la dificultad de las instancias de planeación del Estado, y las consultorías que estas contratan, para realizar ejercicios de planeación desde una escala que les permita interactuar con las personas y conocer las realidades territoriales.

Morelia NEXT es un instrumento que define una prospectiva de cómo en 25 años podemos transformar el municipio, el territorio, y sí incluye o aborda no sólo la visión de un sector especifico sino en general, una relación rural-urbana, económica-social etc., aprovechando la vocación y el potencial ambiental que tiene el municipio, pero digamos que este es un paraguas bajo el cual debe haber muchos otros instrumentos, ahora estamos trabajando en el Programa de Ordenamiento Territorial Municipal, tenemos que hacer la actualización 
de los programas de desarrollo urbano y otros instrumentos (Entrevista realizada el 05 de septiembre de 2017).

El plan Morelia NExT es un producto dónde como señala Lefebvre (2013) la economía y la técnica están involucradas, es una propuesta política de ordenamiento territorial desde la cual se dice dónde debe crecer la ciudad, que infraestructura y proyectos estratégicos deben implementarse, recuperación del rio chiquito y la antigua zona industrial, sistema de transporte masivo, nuevo puerto de carga y descarga. Se trata de un instrumento creado desde el enfoque de gestión empresarial propio de los gobiernos neoliberales (Mattos, 2016).

Por otro lado, la estructuración funcional de las ciudades está estrechamente vinculada con las áreas de donación, su finalidad es el equipamiento y eso debiera ser una prioridad (Rodríguez et al, 2019), sin embargo, es un tema que no ha sido debidamente atendido en términos legales y administrativos, de ahí que estos espacios se conviertan en objeto de invasión y mercantilización (Harvey, 2001).

En la regulación sí está el tema de infraestructura, pero parece que en la práctica no está, es un tema de operación, pero es un asunto entre el Ayuntamiento y las constructoras porque se supone que las áreas de donación no se deben vender de acuerdo a los lineamientos que existen en materia de desarrollo urbano, medio ambiente y asentamientos humanos, así como los ordenamientos federales. Está por salir un dictamen muy importante porque el Congreso del Estado ha tenido serios problemas en materia de áreas de donación por su invasión y venta, se prohibirá su mercantilización, las áreas invadidas no se van a poder regularizar porque en la actualidad la desincorporación del patrimonio estatal está prohibida, ni el ejecutivo puede hacerlo, no solamente es un tema de corrupción también se pierde el sentido del equipamiento urbano que es substancial (Entrevista realizada el 13 de febrero de 2018).

Desde la racionalidad de las leyes se busca frenar las prácticas consideradas ilegales y recuperar el sentido del equipamiento, sin embargo, estos cambios se limitan al contenido instrumental del marco jurídico-normativo, porque en la práctica en principio las áreas de donación son administradas por finanzas, área de la administración desvinculada de la gestión urbana:

Es necesario vincular el departamento de patrimonio (de finanzas) con las instituciones encargada de la gestión urbana porque no sabemos cuáles son los criterios que está tomando esta dependencia para definir los usos de las áreas de donación (Entrevista realizada el 20 y 28 de septiembre de 2017).

Esta segmentación administrativa genera impactos en todos los ámbitos de actuación, en algunos casos los programas urbanos enfrentan dificultades en su aprobación por la existencia de suelos de conservación, además la escala a la cual se elaboran dificulta las acciones preventivas y la solución de problemas a nivel de tenencias y colonias. En muchos casos los programas de desarrollo urbano se han convertido en instrumentos estratégicos para lograr la expansión de la mancha urbana, sin considerar que las grandes ciudades son elementos centrales de la crisis ecológica, su existencia acelera las relaciones depredadoras entre el hombre y el medio e impone mudanzas radicales a la naturaleza (Santos, 2014). 
El poco interés y compromiso que muestran las instituciones en la atención de los temas ambientales y su relación conflictiva con el crecimiento económico explica la insuficiencia de instrumentos y herramientas de control en el tema ambiental:

con Catalina Rosas Monge (Secretaria de Desarrollo Urbano del estado, en periodo 20082012), la autorización de manifestaciones de impacto ambiental (MIAS) fue una caja negra, ise autorizaron sin ton ni son!, sin tomar en cuenta la dirección del desarrollo urbano. Pero cuando se niegan las MIAS se acusa de que se frena el desarrollo económico (Entrevista realiza el 06 de febrero de 2018).

La degradación ambiental tiene origen en las malas decisiones de uso de suelo que han derivado en la ocupación de tierras de uso forestal y agropecuario para el crecimiento urbano (Hernández \& Vieyra, 2010). Por su parte la política de áreas naturales protegidas se ha reducido a una delimitación o zonificación normativa que define restricciones territorializadas y determina perímetros de discriminación positiva, se trata de la construcción territorial de un estatus jurídico especial basado en restricciones que ponen límite a los derechohabientes y regulan la práctica o el uso del derecho de propiedad en nombre del interés público y de la protección de los bienes colectivos o comunes (Melé, 2016:48). En este sentido la relación del ordenamiento territorial con la redistribución y la justicia radica en que la acción pública reparta beneficios y cargas en el disfrute de los recursos bienes, valores y oportunidades espaciales y ambientales, sin embargo en la práctica el ordenamiento territorial "facilita y promueve determinados modelos de utilización del espacio y del entorno, obstaculizando y desalentando otros; satisface preferencias, deseos, necesidades, exigencias y aspiraciones de ciertos individuos o grupos e ignora o sacrifica otros" (Benabent, 2010:122).

El éxito o fracaso de las políticas territoriales de conservación depende en gran medida de la instauración de formas democráticas de gestión, la conservación del medio ambiente no puede lograrse sin tomar en cuenta a la población local. Sin embargo, el principal impacto se da cuando se definen prioridades en el marco de la implementación de políticas de ajuste estructural y se termina por operar una política ambiental basada en decretos y restricciones cuyos costos son asumidos por la población local con desventajas históricas acumuladas (Legorreta \& Márquez, 2012).

Normas y lineamientos muestran que el gobierno mexicano se adscribe formalmente a los propósitos de la estrategia equilibrada y socialmente comprometida para contener el deterioro del ambiente. Sin embargo, en los hechos la política ambiental manifiesta una constante tensión, en la que dominan las orientaciones autoritarias que dan prioridad a medidas prohibitivas y restrictivas (Legorreta y Márquez, 2012:283).

Sin embargo, las restricciones se imponen a determinados sectores de la sociedad, generalmente campesinos o pequeños propietarios, no a los grandes empresarios inmobiliarios que fomentan la expansión urbana, asociada a la destrucción y fragmentación de ecosistemas naturales, la disminución de la diversidad de especies, un mayor riesgo de inundaciones, contaminación del aire y mayor consumo de energía (Torres, 2008). Las instituciones político-administrativas que regulan usos de suelo y recursos naturales enfrentan limitaciones conceptuales e instrumentales para la toma de decisiones: 
En materia ambiental el municipio está muy limitado, como Ayuntamiento puedes observar algunas cosas, pero te tienes que sujetar a normas federales y estatales. Las normas oficiales mexicanas son muy permisivas (en el caso del agua), y existen muchas normas estatales y municipales que no se armonizan con las federales (Entrevista realizada el 29 de enero de 2018).

Con la intervención del sector inmobiliario en los procesos de ordenamiento territorial se han operado una serie de reformas para el saqueo de recursos naturales, que afectan principalmente al sector rural (cuyo régimen de propiedad generalmente es ejidal, en México) que se encuentra en los límites de las ciudades, fenómeno que es razonado por los políticos de la siguiente manera:

Hay ejidos que son totalmente desérticos en los que una hectárea en valor agrícola no representa absolutamente nada. Se tendría que ver su rendimiento, se debe priorizar lo ambiental, los terrenos que no son rentables se los seguirá comiendo la mancha urbana (entrevista realizada el 20 de septiembre de 2017).

Desde la racionalidad de los políticos, los núcleos rurales cercanos a la ciudad se asemejan a personas con enfermedades crónicas que definen su situación de vida, se considera que el arraigo de los campesinos no es generalizado por ello optan por cambiar sus medios y modos de vida. Desde estas posiciones que emergen del empresarialismo urbano se piensa que:

Las ciudades no pueden evitar el crecimiento, no es posible que se frene el desarrollo, se debe analizar qué sucede en cada predio, si la actividad agrícola es útil, si está funcionando, si es rentable. Hasta donde estas apoyando a esta gente que está metida en la mancha urbana, eso debe estar en la planeación, hasta donde llega la competencia, si nosotros debemos orientarlos a que se pasen a otro lugar (Entrevista realizada el 14 de septiembre de 2017)

Existe una sobrevaloración de lo urbano y la ciudad, mientras que el campo, lo rural se encuentra en un lugar de subordinación (López et al., 2005). Esto nos hace pensar que la ciudad seguirá creciendo de manera anárquica a pesar de la existencia de grupos sociales y organizaciones civiles que encabezan luchas aisladas para lograr procesos territoriales más equilibrados.

Es muy difícil que los usos rurales puedan subsistir de aquí a diez años porque la mancha urbana se los está comiendo, y por las condiciones de necesidad que obligan a vender las tierras (entrevista realizada el 13 de febrero de 2018I).

La propuesta de ordenamiento territorial radica en la representación del bien común y objetivos consensuados de desarrollo económico, social y ambiental, este fundamento ético obliga a garantizar a todos los ciudadanos un hábitat digno. Sin embargo, en la actualidad se han confundido los valores fundamentales (felicidad, bienestar) por los instrumentos (dinero y tecnología), así los medios se han convertido en los fines (Valenzuela, 2018). Mientras los gobiernos nacionales y urbanos continúen alineados con los criterios neoliberales, iniciativas como el ordenamiento territorial terminarán siendo buenas intenciones que se mezclarán con las tendencias expansivas de los activos financieros, los agregados monetarios y la mercantilización de la vida en general (Naredo, 2006) 


\section{Conclusiones}

Esta investigación nos permite mostrar las iniciativas de ordenamiento territorial como procesos de producción espacial inmersos en una trama mediaciones institucionales, legales y normativas, en algunos casos contradictorias e irracionales, producto de un juego de fuerzas político-económicas que entran en conflicto en la consecución de objetivos sectoriales o particulares. La relevancia de visibilizar estas tensiones y conflictos subyacentes en la política territorial radica en la posibilidad de una intervención dirigida al entramado jurídico-normativo, generalmente desdeñado desde la investigación científica, que puede llegar a ser definitorio en el éxito o fracaso de propuestas territoriales equilibradas.

De igual forma, este trabajo pone de manifiesto que en el contexto actual las racionalidades de técnicos, planificadores y políticos que promueven territorios inteligentes, innovadores y competitivos, desde un enfoque de gestión empresarial, se ha instalado como la vía para resolver los problemas territoriales, lo cual representa un peligro, ya que se trata de visiones racionales que no interactúan con el espacio local, las racionalidades locales y las prácticas sociales de los actores que habitan el territorio. De ahí que uno de los mayores desafíos en el tema de ordenamiento territorial es la integración efectiva de la ciudadanía en el proceso de elaboración de instrumentos y la aplicación o ejecución de propuestas, así como la articulación de evidencias objetivas, pautas culturales e intereses ocultos y en conflicto. Estas condiciones son elementales para construir líneas de acción que no sean cuestionables en entre todos y lograr un orden territorial equilibrado.

Por otro lado, la investigación nos permite plantear la importancia de que la investigación en el tema de ordenamiento territorial se adentre en el análisis de los conflictos y relaciones de poder que orientan la producción legal y normativa, para poner de manifiesto las tensiones que originan la permanente adaptación del marco jurídico-normativo y plantear líneas generales que ayuden a subsanar las deficiencias administrativas y vacíos legales que impactan de manera significativa el uso y apropiación del territorio.

Hacer visibles las racionalidades político-económicas que trascienden en la producción y aplicación de leyes, los intereses en conflicto, la sectorización normativa y la desarticulación multinivel puede ser una ruta en dirección conciliar intereses que permitan lograr una redistribución justa de ventajas y desventajas producidas a raíz de la implementación de políticas neoliberales en el territorio mexicano. Una redistribución sustentada en el bien común, que alcance a toda la ciudadanía, no sólo los intereses de los sectores económicos y políticos más pujantes, que se traduzca en un ordenamiento territorial social, económica y ecológicamente equilibrado.

\section{Referencias Bibliográfica}

ALLEN, A. Environmental planning and management of the peri-urban interface: perspectives on an emerging field. Environmental and urbanization, 2003, ํo1, p. 135-147.

ARZENO, M. Orden-desorden y ordenamiento territorial como tecnología de gobierno. Estudios Socioterritoriales. Revista de Geografía, 2019, N²5, p. 1-16. 
ÁVILA, H. Periurbanización y gestión territorial. Algunas ideas y enfoques disciplinarios . En: VIEYRA, A. (coordinador) Procesos urbanos, pobreza y ambiente. Implicaciones en ciudades medias y megaciudades. México: UNAM-CIGA, 2016, p. 49-69.

AZUELA, A. La ciudad y sus reglas. Sobre las huellas del derecho en el orden urbano. México: Universidad Nacional Autonoma de México, 2016.

BENABENT, M. El interés general en la folosofía política. Un concepto ético y normativo necesario para la planificación territorial. Boletín de la Asociación de Geografos Españoles, 2010, N 53, p. 121-146.

BLOMLEY, N. \& BKAN, J. Spacing out: Towards a critical geografhy or law. Osgoode Hall Law Journal, 1992, p. 661-690.

CARBALLIDO, M. Crítica del pensamieto crítico. apuntes para pensar las luchas. Revista Latinoamericana de Derechos Humanos, 2015, p. 15-37.

CASTELLS, M. La Cuestión urbana. México D.F.: Siglo XXI, 1974.

COULOMB, R. La gestión de la metrópoli: entre lo público y lo privado. En: COULOMB, R. \& DUHAU, E. (coordinadores) Polítias urbanas y urbanización de la política México : Universidad Autónoma Metropolitana, 1989, p. 97-138.

DELGADO, M. \& GUTIÉRREZ, J. Métodos y técnicas cualitativas de investigación en ciencias sociales. Madrid: Sintesís, 1999.

EIBENSCHUTZ, R. Medio Ambiente, Ciudad y Sostenibilidad. En: MONTAÑO, R. (coordinador) Nuevas ideas y visiones del desarrollo urbano regional. México: Centro de Investigaciones en Geografía Ambiental, El Colegio del Estado de Hidalgo, 2012, p. 111-142.

COMISIÓN EUROPEA. Carta Europea de Ordenación del Territorio.Torremolinos, España : Conferencia de ministros responsables de la ordenación del territorio, 1983.

GASCA, J. Restructuración y polarización entre ciudades y regiones en México durante el neoliberalismo. En: OLIVERA, P. (coordinadora) Polarización social en la ciudad contemporanea. México: Universidad Nacional Autonoma de México, 2013, p. 21-53.

GUBA, E., \& LINCOLN, Y. Paradigmas en competencia en la investigación culitativa . En C. Denman, C. \& Haro, J. (coordinadores). La investigación cualitativa. Hermosillo: El Colegio de Sonora, 2002, p. $113-145$.

HARVEY, D. Espacios del Capital. Hacia una geografía crítica. Madrid: Akal, 2001.

HARVEY, D. Breve historia del neoliberalismo. Madrid: Akal, 2005. 
HERNÁNDEZ, J., \& VIEYRA, A. Riesgo por inundaciones en asentamientos precarios en el periurbano. Morelia, una ciudad media mexicana. ¿el desastre nace o se hace?. Revista de Geografía Norte Grande, 2010, № 47, p. 45-62.

HERNÁNDEZ, Y. El ordenamiento territorial y su construcción social en Colombia: ¿un instrumento para el desarrollo sustentable?. Revista Colombiana de Geografía, 2010, Nº19, p. 97-109.

KEIVANI, R. \& MATTINGLY, M. The interface of globalization and peripheral land in the cities of de south: implications for urban governance and local economic development. International Journal of Urban and Regional Research, 2007, p. 459-474.

LANGBEHN, L. Conflictos y controversias por el Ordenamiento Territorial de Bosques Nativos en Salta: la cuestión ambiental y el control sobre el territorio. En: MERLINSKY, G. (coordinador). Cartografías del conflicto ambiental en Argentina, Buenos Aires: Ediciones CICCUS, 2013, p. 223-254.

LEFEBVRE, H. La Producción del Espacio. Madrid: Capitán Swing, 2013.

LEGORRETA, M. \& MÁRQUEZ, C. Democracia, desigualdad y política ambiental en las reservas de la biosfera en México. Un enfoque interdisciplinario. En: DURAND, L., FIGUEROA, F. \& GUZMAN, M. (coordinadores). La naturaleza en contexto. Hacia una ecológia política mexicana. México: Universidad Nacional Autónoma de México, Colegio de San Luis, 2012, p. 269-294.

LOJKINE, J. El marxismo, el estado y la cuestión urbana. México: Siglo XXI.,1976

LÓPEZ-PÉREZ, J. D. Interfase urbano rural como territorio y espacio para la sostenibilidad ambiental. Revista Ingenierías Universidad de Medellin, 2005, № 7, p. 29-41.

MASSIRIS, Á. Políticas latinoamericanas de ordenamiento territorial:realidades y desafíos. Tunja: Universidad pedagógica y tecnológica de Colombia, 2006.

MATTOS, C. Financiarización y mercatilización del desarrollo urbano en escala planetaria . Andamios, 2016, p. 213-243.

MATTOS, C. Impactos de la financiarización inmobiliaria y la mercantilización de la metamorfosis urbana . En: GASCA, J. (coordinador). Capital Inmobiliario. Producción y transgresión del espacio social en la ciudad neoliberal. México: Instituto de Investigaciones Económicas de la Universidad Nacional Autónoma de México, 2019, p. 17-49.

MELÉ, P. Incertidumbre y regulaciones urbanas: el papel de la calificación jurídica del espacio. En: AZUELA, A. (coordinador). La ciudad y sus reglas. Sobre la huella del derecho en el orden urbano México: Universidad Nacional Autónoma de México, Instituto de Investigaciones Sociales y PAOT, 2016, p. 43-82.

MÉNDEZ, E. Ordenamiento territorial-ambiental: desarrollo responsable y sostenible. Revista Geográfica de Venezuela, 2000, №2, p. 281-301. 
NAREDO, J. M. Raices económicas del deterioro ecológico y social: más alla de los dogmas. Madrid: Siglo XXI, 2006.

NEUMANN, P. \& HIDALGO, R. Políticas de vivienda y reestructuración de áreas centrales de ciudades portuarias sudamericanas. En: SANTANA, D., ALVARADO, V. \& HIDALGO, R. (editores) Las Geografías del Neoliberalismo en América del Sur. Santiago de Chile: Instituto de Geografía de la Pontificia Universidad Catolica de Chile, 2019, p. 177-199.

OSORIO, J. Fundamentos del análisis social. México: Fondo de Cultura Económica, 2001.

RAVETZ, J., CHRISTIAN, F. \& NIELSEN, T. The dynamics of peri-urbanization. En: NILSSON, K. PAULEIT, S. BELL, S. \& AALBERS, C. (coordinadores) Peri-urban futures:Scenarios and models for land use change in Europe. Berlin Heidelberg: Springer-Verlag, 2013, p. 13-44.

RAWLS, J. Teoria de la Justicia. México: Fondo de Cultura Económica, 1997.

RODRIGUEZ, N., VIEYRA, A., \& GONZÁLEZ, O. (2019). El periurbano y los grandes proyectos inmobiliarios: los casos de Altozano y Tres Marías en Morelia, Michoacán. En: GASCA J. (coordinador). Capital inmobiliario. produción y transgresión del espacio social en la ciudad neoliberal. México : Universidad Nacional Autónoma de México, Instituto de Investigaciones Económicas, 1997, p. 299-318.

SÁNCHEZ, M., CASADO, J. \& BOCCO, G. La política de ordenamietno territorial en México: de la teoria a la práctica. Reflexiones sobre sus avances y retos a futuro. En SÁNCHEZ, M., BOCCO, G. \& CASADO, J. (coordinadores). La política de ordenamietno territorial en México: de la teoria a la práctica. Morelia : Universidad Nacional Autónoma de México, Instituto de Geografía, Centro de Estudios en Geografía Ambiental, Secretaría de Medioa Ambiente y Recursos Naturales, Instituto Nacional de Ecología y Cambio Climatico, 2013, p. 19-44.

SANTOS, M. Manual de Geografía Urbana (Tercera edición ed.). São Paulo: Edusp, 2012.

SANTOS, M. A naturaleza do espaço (4a ed.). São Paulo: Edusp, 2014.

SASSEN, S. Hacía una proliferación de ensamblajes especializados de territorio, autoridad y derechos. Cuadernos del CENDES, 2006, № 62, p. 95-112.

SAURI, D. Geografía, marcos legales y recursos hidráulicos. Boletin de la Asociación de Geografos Españoles,1989, p. 97-108.

SCHMIDT, M. "Ordenadores y ordenados". Actores en disputa en el ordenamiento territorial de bosques nativos en la provincia de Salta. Cuadernos de Antropología, 2014, no 11, p. 37-55.

SIETCHIPING, R., KAGO, J., ZHANG, X. Q., AUGUSTINUS, C., \& TUTS, R. Role of urban-rural linkages in promoting sustainable urbanization. Environment and Urbanization ASIA, 2014, N 2, p. 219-234. 
SILI, M. Acción territorial y construcción del desarrollo. Experiencia de zonas rurales de la Pampa Argentina. Revista de Geografía Norte Grande, 2019, № 74, p.159-186.

TORRES, H. Social and environmental aspects of peri-urban growth in Latin American Megacities. New York: UN/POP/EGM-URB/, 2008.

VALDEBENITO, C., \& ALVAREZ, L. Entre el uso público y el aprovechamiento privado: tensiones y desafíos al ordenamiento territorial de la conurbación costera del área metropolitana de Valparaíso. En: HIDALGO, R., SANTANA, D., ALVARADO, V., ARENAS, F., SALASAR, A., VALDEBENITO, C. \& ALVAREZ, L. (editores). En las costas del neoliberalismo. Naturaleza, urbanización y producción inmobiliaria: experiencias en Chile y Argentina. Santiago de Chile : Instituto de Geografía de la Pontificia Universidad Catolica de Chile, 2016, p. 82-104.

VALENCIA, P. Consideraciones jurídicas sobre el ordenamiento territorial ambiental. Revista espacio y Desarrollo, 2009, № 21, p.139-169.

VALENZUELA, C. Ordenamiento territorial y transporte: una aproximación ética a la planivicación participativa de la ciudad. En: CORREA, M., ARENAS, F. \& ALVARADO, V. (editores). Ética en Geografía. Santiago de Chile: Instituto de Geografía de la Pontificia Universidad Católica de Chile, 2018, p. 176-196.

ZOIDO, F. Geografía y ordenación del territorio. Geografía e Historia, 1998, p. 19-31. 
